\title{
Powder for Gingival Gel Dosage Form
}

National Cancer Institute

\section{Source}

National Cancer Institute. Powder for Gingival Gel Dosage Form. NCI Thesaurus. Code C149827.

Solid preparation consisting of one or more powders intended to be mixed with the specified liquid or gel to obtain a gingival gel. 